\title{
Care time and quality indicators in Intensive Care Units
}

\author{
Tempo de assistência e indicadores de qualidade em Unidades de Terapia Intensiva \\ Tiempo de atención e indicadores de calidad en Unidades de Terapia Intensiva
}

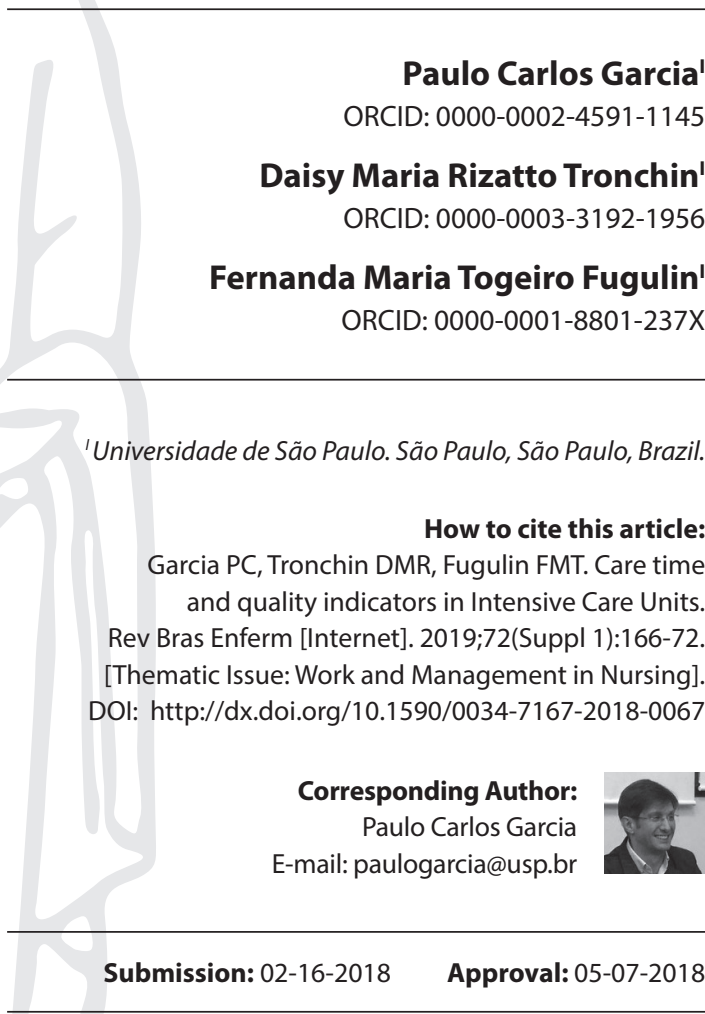

\begin{abstract}
Objective: To verify the correlation between nursing care time and care quality indicators. Method: Observational, correlational study, developed in 11 Intensive Care Units. The population comprised records of the number of nursing professionals, the number of patients with at least one of the Oro/Nasogastroenteral Probe (GEPRO), Endotracheal Tube (COT) and Central Venous Catheter (CVC) therapeutic devices and the occurrences related to the losses of these artifacts. Results: The time corresponded to 18.86 hours (Hospital A), 21 hours (Hospital B) and 19.50 hours (Hospital C); the Unplanned Outflow Incidence of GEPRO indicator presented a mean of 2.19/100 patients/day; Unplanned Extubation of COT Incidence, $0.42 / 100$ patients/day; and CVC Loss Incidence, $0.22 / 100$ patients/day. There was no statistically significant correlation between time and indicators analyzed. Conclusion: This research may support methodological decisions for future investigations that seek the impact of human resources on the care quality and patient safety.

Descriptors: Nursing; Administration of Human Resources in Health; Quality Indicators in Health Care; Intensive Care Unit; Work Load.
\end{abstract}

\section{RESUMO}

Objetivo: Verificar a correlação entre tempo de assistência de enfermagem e indicadores de qualidade assistencial. Método: Estudo observacional, correlacional, desenvolvido em 11 Unidades de Terapia Intensiva. A população compreendeu registros do quantitativo dos profissionais de enfermagem, do número dos portadores de, ao menos, um dos dispositivos terapêuticos Sonda Oro/Nasogastroenteral (SONGE), Cânula Endotraqueal (COT) e Cateter Venoso Central (CVC) e das ocorrências relativas às perdas desses artefatos. Resultados: O tempo correspondeu a 18,86 horas (Hospital A), 21 horas (Hospital B) e 19,50 horas (Hospital C); o indicador Incidência de Saída Não Planejada de SONGE apresentou média de 2,19/100 pacientes/dia; Incidência de Extubação não Planejada de COT, 0,42/100 pacientes/dia; e Incidência de Perda CVC, 0,22/100 pacientes/dia. Não houve correlação estatisticamente significante entre o tempo e os indicadores analisados. Conclusão: Esta pesquisa pode apoiar decisões metodológicas para investigações futuras que buscam o impacto dos recursos humanos na qualidade assistencial e segurança dos pacientes. Descritores: Enfermagem; Administração de Recursos Humanos em Saúde; Indicadores de Qualidade em Assistência à Saúde; Unidade de Terapia Intensiva; Carga de Trabalho.

\section{RESUMEN}

Objetivo: Verificar la correlación entre tiempo de atención de enfermería e indicadores de calidad asistencial. Método: Estudio observacional, correlacional, desarrollado en 11 Unidades de Terapia Intensiva. La población comprendió registros del cuantitativo de los profesionales de enfermería, del número de portadores de, al menos, uno de los dispositivos terapéuticos Sonda Oro/Nasogastroenteral (SONGE), Cánula Endotraqueal (COT) y Cateter Venoso Central (CVC) y de las ocurrencias relativas a las pérdidas de estos artefactos. Resultados: El tiempo correspondió a 18,86 horas (Hospital A), 21 horas (Hospital B) y 19,50 horas (Hospital C); el indicador Incidencia de Salida No Planeada de SONGE presentó una media de 2,19/100 pacientes/día; Incidencia de Extubación no planificada de COT, 0,42/100 pacientes/día; e Incidencia de Pérdida CVC, $0,22 / 100$ pacientes/día. No hubo correlación estadísticamente significativa entre el tiempo y los indicadores analizados. Conclusión: Esta investigación puede apoyar decisiones metodológicas para investigaciones futuras que buscan el impacto de los recursos humanos en la calidad asistencial y seguridad de los pacientes.

Descriptores: Enfermería; Administración del Personal en Salud; Indicadores de Calidad en Atención de Salud; Unidad de Terapia Intensiva; Carga de Trabajo. 


\section{INTRODUCTION}

The decision-making process on the issues related to the quantitative and qualitative adequacy of nursing professionals, in face of the health care quality and safety standards sought by the health services can be demonstrated by the association between nursing care time spent on patients and quality indicators. This association can be an important management tool(1).

In this direction, studies ${ }^{(2-3)}$ seek to demonstrate the correlation between different variables involved in the care process, in order to qualify the offer of better services to meet the patient care needs.

However, one of the limiting factors for the establishment of possible associations between these variables refers to the methodological designs of the investigations, which present inconsistencies related to the diversity of data sources, to the methods of obtaining the nursing staff and to the intervening variables in the results of the care ${ }^{(3)}$.

In Brazil, a study carried out with the objective of analyzing the time used by the nursing team to assist patients hospitalized in an Adult Intensive Care Unit (ICU), as well as to verify its correlation with care quality indicators, found a negative correlation between the time of nursing care provided by nurses and the Unplanned Extubation indicator (UPE) of Endotracheal Tube, demonstrating that the longer the care provided by nurses, the lower the UPE indicator ${ }^{(1)}$.

In the same direction, research developed in the Pediatric and Neonatal Intensive Care Unit (PNICU) evidenced a positive correlation between the nursing care time and the Unplanned Overflow Incidence of Oro/Nasogastroenteral Probe (GEPRO) for nutritional intake. The authors concluded that the availability of time influences the notifications or underreporting of these events, but does not support the hypothesis that care quality indicators are altered as a function of the mean time of care given to patients admitted to the PNICU ${ }^{(4)}$.

Thus, these findings ${ }^{(1,4)}$ point to the need for new investigations that contemplate other realities/services. This finding is corroborated by recent research ${ }^{(5)}$, published in the international setting, that despite the generation of data and studies on the impact and contribution of the number of nursing professionals to the quality and safety of care provided to patients, considers that this type of research continues to represent a challenge for the quantification of evidence that supports and favors the decision-making and negotiation processes related to the quantitative and qualitative of nursing professionals.

In this sense, in order to contribute to the scientific knowledge in Nursing and the development of a method that allows demonstrating the impact of the nursing staff in the results of the assistance, the present research was delineated with the objective to follow.

\section{OBJECTIVE}

To verify the correlation between the mean time of nursing care given to adult patients hospitalized in Intensive Care Units (ICU) in the city of São Paulo and the following care quality indicators: Unplanned Outflow Incidence of Oro/Nasogastroenteral Probe for Nutritional Contribution (UPOI of GEPRO); Unplanned Extubation Incidence of Endotracheal Tube (UPEI of COT); of Central Venous Catheter Loss Incidence (CVC LI).

\section{METHOD}

\section{Ethical aspects}

The research project was submitted to the Brazil Platform and approved by the Research Ethics Committee (REC) of the School of Nursing of the Universidade de São Paulo (EEUSP). In addition, it was authorized by the Ethics Committees of the participating institutions and conducted in accordance with the recommendations of Resolution 466 of 2012 of the National Health Council (Conselho Nacional de Saúde)/Ministry of Health.

\section{Design, place of study and period}

It is a quantitative, observational and correlational study developed in the ICU of adult patients from three hospitals located in the city of São Paulo, selected for being typical representatives of public (two) and private (one) institutions and meeting the following criteria: to have nurses in all work shifts; develop the Nursing Process; to have a continuing education service or to develop training programs and development of nursing personnel; (GEPRO, COT, CVC) monitored by means of indicators and assistance protocols implemented for the handling of such artifacts.

The hospitals were identified by the letters A and B, drawn between public hospitals, and the letter $C$ used to nominate the private hospital. The letter $\mathrm{H}$ represents the hospital citation. In order to identify ICU, according to the institution, these units were nominated according to hospital letter, plus numbering from one to 11, according to the sequence of their presentation.

The HA is a general, public and educational institution, with 280 beds, of which 12 are located in the ICU of adult patients, denominated as HA1.

$\mathrm{HB}$ is also a general hospital, public and teaching, high complexity, characterized as tertiary care. In the data collection period, there were 948 active beds, of which 98 were for intensive care, distributed in nine units, identified as HB2 (19 beds), HB3 (10 beds), HB4 (04 beds), HB5), HB6 (11 beds), HB7 (9 beds), HB8 (17 beds), HB9 (14 beds) and HB10.

The $\mathrm{HC}$ is private. Characterized as of tertiary care and has 324 beds. At this institution, the study took place at the ICU, named $\mathrm{HC} 11$, which had, during the data collection period, 37 active beds.

Data collection in the HA and HB occurred between July 17 and November 17, 2015, and in the period between August 12 and December 12, 2015.

\section{Population and criteria of inclusion and exclusion}

The population comprised the quantitative and qualitative records of nursing professionals in activity in the Units studied, the number of patients with at least one of the therapeutic devices (GEPRO, COT, CVC) and the occurrences related to device losses.

\section{Study protocol}

The mean time of nursing care provided to the patients was calculated electronically by applying equation $(1)^{(6)}$ :

$$
\overline{h_{k i}}=\frac{q_{k i} \cdot t_{k i}}{\bar{n}_{i}}
$$


Where:

$\overline{h_{k i}}=$ mean time of nursing care, per patient, spent by the professional category $k$, at duty $i$;

$k=$ professional category (nurse, nursing technician/assistant);

$i=$ period (morning, afternoon, night);

$q_{k i}=$ mean number of nursing staff in professional category $k$ at duty $i$;

$t_{k i}=$ time of the professional workday $k$ at duty $i$ (six hours);

$\overline{n_{i}}=$ mean daily number of patients served at duty $i$.

For the operationalization of this stage, the data referring to the mean number of nursing professionals, by category, according to the shifts (morning, afternoon and night) were collected through consultation of the daily quantitative and qualitative records (daily work distribution scales).

Professionals who were in the training/experience period, undergraduate/nursing residency trainees and/or technician nursing students were not included in the distribution of activities, and consequently, of the workload of the Units because they were not fully qualified for care, without follow-up.

On a daily basis, nurses from the ICU were consulted in order to clarify if there was a professional and/or student on the daily work distribution scales under the conditions described above.

For this consultation, it was requested the signing of the Informed Consent Term. Information on the number of hospitalized patients and patients with therapeutic artifacts (GEPRO, COT and (VC), as well as on incidents related to accidental losses were collected through daily consultations with management tools (daily reports by nurses) and/or consulted the nurses who were on duty at the time of the visit of the member of the data collection team, which took place every day of the week (Monday to Sunday), in the evening, in order to ensure the identification of the avoid possible inconsistencies of the records.

This team consisted of the researcher, a nurse and four students from the last semester of the undergraduate nursing course. The training was conducted by the researcher, with extensive experience in intensive nursing care and occurred over a period of one week (seven days) in all participating institutions.

At first, a meeting was held with the five collaborators, with a mean duration of two hours, to present the research objectives, places of study, operation of the data collection, reading and explanation of the tools to be employed, as well as clarification of questions related to their fulfillment.

In order to operationalize the data collection, visits were made to the ICU that integrated the research fields, in order to explain to the managers and nursing professionals of the Units the purpose of the study and the procedures involved in collecting the specific information; present the data collection team; provide the employees with the recognition of the settings and identification of the location of the management tools to be consulted.

All activities were monitored by the researcher, who remained at the disposal of the team of collaborators during the data collection and was in the study settings at least once a week.

The quality indicators were calculated according to the definitions and equations indicated in the Manual of Nursing Indicators of the Núcleo de Apoio à Gestão Hospitalar (freely translated as Hospital Management Support Center) ${ }^{(7)}$.
In order to avoid possible sources of bias, during the study period there were no changes in the marks of tubes, probes or catheters, in the types of dressings of Central Venous Catheter, as well as in the methods/procedures of fixation of the therapeutic artifacts used in the Institutions, being followed the previously established care protocol.

For the sample calculation, a regression model with incidence of the unplanned loss events of the therapeutic artifacts (GEPRO, COT and (VC) of $2 \%$ was adopted by assumption. It was also assumed that for each additional patient per nursing professional, the chance of unplanned loss of therapeutic artifacts would be double the number estimated in this prediction, equivalent to a chance ratio of two, with a confidence interval of $95 \%$ and test power of $80 \%{ }^{(8)}$.

Thus, the minimum sample to analyze possible correlations would be 695 observations of patients' records at risk of losses referring to each therapeutic artifact, in each work shift. However, considering that the indicators portray the monthly incidence of artifact losses, we opted for a period of four months of data collection, which considerably increased the number of observations of patients with risk of loss of therapeutic artifacts, robustness required in studies with correlational designs.

\section{Results analysis and statistics}

For the quantitative variables, measures of central tendency (mean, maximum and minimum) and dispersion (Standard Deviation (SD) were calculated). Subsequently, data analysis was performed based on descriptive and inferential statistics. The correlation of the variables, mean nursing care time and quality indicators, was tested using the Spearman Correlation Coefficient, using a $5 \%$ level of significance ( $p$ value $<0.05$ ). The confidence interval adopted corresponded to $95 \%$.

\section{RESULTS}

During the data collection period, 2,569 patients were assisted in the ICU that were included in the study. The majority of the patients were male (55.60\%) and elderly (77.00\%). The mean age was 55.67 years $(S D=20.72)$.

The mean time of care given to patients hospitalized in the ICU, according to the hospital institution, is described in Table 1.

During the study period, 13,593 records of the presence of patients at risk of GEPRO loss were found. The mean of the indicator, in the three hospitals, corresponded to $2.19 / 100$ patient-days ( $S D=10.93$ ).

As for the therapeutic artifact COT, 8,052 recorded observations of patients at risk of loss were computed. The indicator presented a mean of $0.42 / 100$ patient/days $(S D=4.51)$.

In relation to patients at risk of loss of CVC therapeutic artifact, there were 21,275 records. The mean of the indicator in the three hospitals was $0.22 / 100$ patient/days (SD $=2.04$ ).

Regarding the characterization of the losses of artifacts GEPRO, COT and CVC, there were 362 losses. As for the type of artifact, it was observed $74.31 \%$ of losses related to GEPRO. The patients were responsible for the losses in $82.04 \%$ of the situations.

The data in Table 2 show the correlation analysis between mean time of care given to patients and care quality indicators. 
Table 1- Distribution of the mean time of nursing care given to patients admitted to Intensive Care Units, according to Hospital and Professional Category, São Paulo, Brazil, 2015

\begin{tabular}{|c|c|c|c|c|c|c|}
\hline Hospitals & Mês & $\begin{array}{l}\text { Mean Time } \\
\text { Total (h) }\end{array}$ & $\begin{array}{c}\text { Nurse Mean } \\
\text { Time (h) }\end{array}$ & (\%) & $\begin{array}{l}\text { Nursing Technician/ } \\
\text { Assistant Mean } \\
\text { Time (h) }\end{array}$ & (\%) \\
\hline \multirow[t]{4}{*}{$\mathrm{HA}$} & Mean & 18.86 & 7.12 & 37.75 & 11.74 & 62.24 \\
\hline & Maximum & 20.60 & 7.79 & 38.23 & 12.81 & 62.91 \\
\hline & Minimum & 16.84 & 6.38 & 37.09 & 10.46 & 61.77 \\
\hline & SD & 1.55 & 0.54 & 0.40 & 1.01 & 0.40 \\
\hline \multirow[t]{4}{*}{$\mathrm{HB}$} & Mean & 21.00 & 7.35 & 35.00 & 13.65 & 65.00 \\
\hline & Maximum & 22.10 & 7.65 & 36.90 & 14.45 & 65.90 \\
\hline & Minimum & 20.54 & 7.07 & 34.10 & 12.97 & 63.10 \\
\hline & SD & 0.64 & 0.26 & 1.11 & 0.53 & 1.11 \\
\hline \multirow[t]{4}{*}{$\mathrm{HC}$} & Mean & 19.50 & 8.06 & 41.36 & 11.44 & 58.65 \\
\hline & Maximum & 20.91 & 8.41 & 42.64 & 12.50 & 59.78 \\
\hline & Minimum & 18.95 & 7.82 & 40.22 & 10.88 & 57.36 \\
\hline & SD & 0.82 & 0.23 & 0.91 & 0.63 & 0.91 \\
\hline
\end{tabular}

Note: (*) Nursing Technician/Assistant; SD: Standard Deviation.

Table 2 - Correlational analysis among the mean time of care provided to the patients, according to professional nursing category and care quality indicators, São Paulo, Brazil, 2015

\begin{tabular}{|c|c|c|c|c|c|c|}
\hline \multirow{3}{*}{ Variables } & \multicolumn{6}{|c|}{ Correlations } \\
\hline & \multicolumn{2}{|c|}{$\begin{array}{l}\text { Unplanned Outflow } \\
\text { Incidence of GEPRO }\end{array}$} & \multicolumn{2}{|c|}{$\begin{array}{l}\text { Unplanned Outflow } \\
\text { Incidence of COT }\end{array}$} & \multicolumn{2}{|c|}{$\begin{array}{l}\text { Unplanned Outflow } \\
\text { Incidence of CVC }\end{array}$} \\
\hline & $\begin{array}{l}\text { Spearman } \\
\text { Correlation }\end{array}$ & $p$ value & $\begin{array}{l}\text { Spearman } \\
\text { Correlation }\end{array}$ & $p$ value & $\begin{array}{l}\text { Spearman } \\
\text { Correlation }\end{array}$ & $p$ value \\
\hline Mean time spent by the team & 0.009 & 0.583 & 0.004 & 0.799 & -0.007 & 0.660 \\
\hline Mean time spent by nurses & 0.003 & 0.841 & 0.007 & 0.635 & 0.003 & 0.863 \\
\hline Mean time spent by technician/assist* & 0.009 & 0.575 & 0.008 & 0.620 & -0.011 & 0.478 \\
\hline
\end{tabular}

Note: (*) Nursing technician/assistant; GEPRO - Oro/Nasogastroenteral Probe; COT - Endotracheal Tube; CVC - Central Venous Catheter.

\section{DISCUSSION}

The characterization of the patients hospitalized in the ICU fields of study demonstrated a biological and social profile compatible with the referendum in the literature ${ }^{(1,9-10)}$.

The mean time of nursing care provided to the patients served at the ICU of the three hospitals presented variations throughout the months studied. Comparing the findings with the minimum recommended by Resolution 0543/17 of the Federal Nursing Council (Cofen - Conselho Federal de Enfermagem) (11), it is observed that the mean hours of nursing care dispensed remained above that recommended by Resolution $0543 / 17^{(11)}$ (18 hours per patient/day).

Likewise, when faced with the mean times of care indicated in Resolution of the Collegiate Board (RDC - Resolução da Diretoria Colegiada) 26 of the National Agency of Sanitary Surveillance (Anvisa - Agência Nacional de Vigilância Sanitária) ${ }^{(12)}$, the mean times of care in the three Institutions exceed that proposed by (14.4 hours per patient/day).

However, with regard to the distribution of the time of nursing care dispensed, among the different professional categories, it is verified that in all the institutions, the percentage of the time of assistance given by nurses was lower than the minimum recommended by Cofen ${ }^{(11)}(52 \%)$.
In spite of this, the percentage of nursing care provided by the nurses of the three institutions was higher than the ratio indicated in RDC 26 ${ }^{(12)}(20 \%)$.

A study ${ }^{(13)}$ that aimed to examine the most appropriate ways to measure nursing hours and predict their relationship with the results of care, pointed as a reference the value of 15.45 hours of care, including time spent with continuing education.

The ideal setting would be to find a greater time of care provided by nurses, since research ${ }^{(2,14)}$ has shown an inversely proportional trend between the increase in levels of nurses and adverse events, such as associated pneumonia to mechanical ventilation, pressure injury, and urinary tract infection and lower chance of death in ICU.

Regarding the quality indicators listed in the present research, it is verified in the national literature that the UPOI of GEPRO corresponded to the mean of $2.33 / 100$ patients/day $(S D=1.51)^{(1)}$.

Research ${ }^{(15)}$ aimed at evaluating the care practice of gastric intubation for enteral nutrition of patients in the Home Care Program (PAD - Programa de Assistência Domiciliar), described the UPOI of GEPRO rate of $0.80 / 100$ patients/day.

Investigation ${ }^{(16)}$ that aimed to verify the occurrence of adverse events related to enteral nutrition in patients of a public hospital in the interior of the state of Rio Grande do Sul showed UPOI of GEPRO of $7.3 \%$ in ICU. 
A systematic review of the literature ${ }^{(17)}$, developed in order to investigate the relationship between devices and techniques to prevent displacement, discomfort and possible complications of GEPRO in adult patients, described the incidence of artifact loss of $28.9 \%$.

In the same direction, a systematic review of the literature ${ }^{(18)}$, which assessed the efficacy of nasal fixations compared to the traditional method of adhesive tape, described tube displacement in $40 \%(138 / 341)$ of patients with traditional fixation and $14 \%(28 / 203)$ for the fastening devices tested.

These findings point to a variability of calculation, making it difficult to compare the studies. However, the mean of this study is higher than those found in the literature.

Thus, the relevance of the investigations that consider the relationship between GEPRO UPOI for nutritional intake, using the same equation for the calculation and the causal factors investigated in the literature, including the costs resulting from the negative results of the care, due to the insufficiency of nursing professionals.

Regarding the UPEI of COT, it was a study ${ }^{(1)}$ that analyzed, for two years, the respective indicator found an mean value of $0.73 / 100$ patients/day $(S D=0.57)$.

Research ${ }^{(19)}$ developed in Spain identified the UPEI of COT of $0.92 / 100$ days of ventilation. A study ${ }^{(20)}$ conducted in the USA, with 190 subjects, reported UPEI of COT of $15 \%$.

In the same line, research ${ }^{(21)}$ conducted in the Netherlands observed $2.1 \%$ of UPEI of COT. The authors further point out that the low UPEI of COT is partly explained by the high ratio of nurses/patients in the ICU field of study.

Systematic review of the literature ${ }^{(22)}$ found a rate of 0.1 to 3.6 events per 100 days of intubation.

A study ${ }^{(23)}$ developed at University Hospital of the University of Taiwan, found UPEI of COT of $2.1 \%$. A recent editorial ${ }^{(24)}$ indicates that UPEI of COT is a measurable and comparable metric among institutions. They criticize the different metrics and call attention to the fact that the event is avoidable, and it is necessary to understand the care systems to prevent their occurrence.

Regarding the LI of CVC, a prospective study ${ }^{(25)}$, with the objective of analyzing the incidence of accidental loss of all types of catheters in the ICU, found the value of 1.12/100 day catheters.

A research ${ }^{(26)}$ developed in the city of São Paulo, with the objective of characterizing adverse events in ICU, found incidence of $0.29 \%$ of CVC-related adverse events.

From the above, it can be seen that the LI of CVC in ICU can be considered a health assessment measure. However, the comparability between realities and health services has also been hampered by the use of different metrics.

As for the characterization of the losses of the therapeutic artifacts, it is emphasized that the concept necessary to treat errors/events, is the implementation of fair culture, encouraging people to communicate events ${ }^{(27)}$.

In addition, providing courses and training on systems for reporting adverse events, providing feedback to health team professionals, implementing the use of quality indicators and monitoring their historical series is also necessary, as management tools in health institutions.

Regarding the correlational analysis among mean time of care provided to the patients, according to the professional category of nursing and care quality indicators, it was verified that the mean times of nursing care, in all professional categories analyzed, presented positive correlations with the UPOI of GEPRO and UPOI of COT indicators.

Regarding the UPOI indicator of CVC and mean time dispensed by the team and mean time dispensed by nursing technician/ assistant, a negative correlation was observed. However, the correlation of this same indicator with the mean time provided by nurses showed a positive correlation.

Contrary to expectations, it was observed that the correlations found in the present study were not statistically significant.

A recent systematic review study ${ }^{(28)}$ pointed out that the evidence base for associations between the nursing human resources framework and the outcomes/care quality is composed exclusively of observational studies. These have certain limitations depending on sample size and specific sources of bias, recognized through a conceptual framework identified as endogenous.

Endogeneity refers to different forms of distortion in association estimation. When assessing the relationship between staff and patient outcomes, they may, for example, be due to uncollected variables, concurrency, and variance of the common method ${ }^{(29)}$.

The non-collected variables may involve the legal nature of the hospital (public, private, teaching), the human resources management model, the competence of the health team professionals and the practice environment ${ }^{(28)}$.

Concerning simultaneity, although studies examining the association between the nursing staff and the outcomes of care assume a direct causality (relation between the number of nursing staff and the results of care), other variables may influence the results of care, such as age, diagnosis, workload required by patients, institutional protocols, among others ${ }^{(28)}$.

The variance of the common method involves elements such as nurses' opinions regarding the results of care and work environment variables, such as job satisfaction and the perception of care quality ${ }^{(28)}$.

\section{Study limitations}

It is considered that some factors may have influenced the results obtained in the present investigation, such as: absence of consultation of records of the medical records regarding the circumstances involved in the loss of therapeutic artifacts, making it impossible to identify the real reasons that determined the losses; teamwork; biological and social variables; the professional qualification of the nursing team; and the environment of practice.

\section{Contributions to the sectors of Nursing, Health or Public Policy}

This study advances to elucidate other variables that may be related to the occurrence of adverse events related to therapeutic artifacts (GEPRO, COT and CVC) and to influence the results of its correlation with the nursing professionals.

\section{CONCLUSION}

The results of the present study may support methodological decisions to transcend technical/scientific knowledge in nursing and conduct investigations that seek to demonstrate the impact 
of nursing human resources on the quality and safety of patients, professionals and health institutions.

Future research, which adds other variables related to the quantitative/qualitative of nursing human resources to patients and adverse events, may find an association, with statistical significance among the indicators, contributing to the generation of evidence that ratifies the interaction between the professional staff nursing care and care outcomes.

\section{REFERENCES}

1. Garcia PC, Fugulin FMT. Nursing care time and quality indicators for adult intensive care: correlation analysis. Rev. Lat Am Enfermagem [Internet]. 2012 [cited 2017 Oct 28];20(4):651-8.Available from: http://dx.doi.org/10.1590/S0104-11692012000400004. English, Portuguese, Spanish

2. McGahan M, Kucharski G, Coyer F. Nurse staffing levels and the incidence of mortality and morbidity in the adult intensive care unit: a literature review. Aust Crit Care. 2012;25(2):64-77. doi:10.1016/j.aucc.2012.03.003

3. Brennan CW, Daly BJ, Jones KR. State of the Science: The Relationship Between Nurse Staffing and Patient Outcomes. West J Nurs Res [Internet]. 2013 [cited 2016 Aug 28];35(6):760-94. Available from: http://journals.sagepub.com/doi/pdf/10.1177/0193945913476577

4. Vieira FP, Garcia PC, Fugulin FM. Nursing care time and quality indicators at a pediatric and neonatal Intensive Care Unit. Acta Paul Enferm [Internet]. 2016 [cited 2017 Oct 28];29(5):558-64. Available from: http://dx.doi.org/10.1590/1982-0194201600077. English, Portuguese.

5. Leary A, Tomai B, Swift A, Woodward A, Hurst K. Nurse staffing levels and outcomes - mining the UK national data sets for insight. Int J Health Care Qual Assur. 2017;30(3):235-47. doi: 10.1108/IJHCQA-08-2016-0118

6. Gaidzinski RR, Fugulin FMT. Dimensionamento de pessoal de enfermagem em unidade de terapia intensiva. In: Associação Brasileira de Enfermagem; coordenadora geral: Maria Madalena Januário Leite. (Org.). Programa de atualização em Enfermagem: Saúde do adulto (PROENF) - Ciclo 3 - Módulo 3. Porto Alegre: Artmed/Panamericana, 2008, p. 65-96.

7. Compromisso com a Qualidade Hospitalar (CQH). Manual de indicadores de enfermagem NAGEH/Compromisso com a Qualidade Hospitalar (CQH). 2 ed. São Paulo: APM/CREMESP, 2012. 60 p.

8. Devane D, Begley CM, Clarke M. How many do I need? Basic principles of sample size estimation. J Adv Nurs. 2004;47(3):297-302. doi: 10.1111/j.1365-2648.2004.03093.x

9. Puchades R, González B, Contreras M, Gullón A, Miguel R, Martín D, et al. Cardiovascular profile in critically ill elderly medical patients: Prevalence, mortality and length of stay. Eur J Intern Med. 2015; 26(1):49-55. doi: 10.1016/j.ejim.2014.12.010.

10. Nogueira LS, Ferreti-Rebustini RE, Poveda VB, Silva RC, Barbosa RL, Oliveira EM, et al. Nursing workload: is it a predictor of healthcare associated infection in intensive care unit? Rev Esc Enferm USP [Internet]. 2015 [cited 2017 Oct 28];49(n. esp):36-42. Available from: http:// dx.doi.org/10.1590/S0080-623420150000700006. English, Portuguese.

11. Conselho Federal de Enfermagem. Resolução n. 543, de 2017 de 18 de abril de 2017. Atualiza e estabelece parâmetros para o dimensionamento do quadro de profissionais de enfermagem nos serviços/locais em que são realizadas atividades de enfermagem [Internet]. Brasília: COFEN; 2017 [cited 2018 Sep 09]. Available from: http://www.cofen.gov.br/wp-content/uploads/2017/05/ RESOLU\%C3\%87\%C3\%830-COFEN-N\%C2\%BA-543-2017-completa.pdf

12. Ministério da Saúde (BR), Agência Nacional de Vigilância Sanitária (ANVISA). Resolução - RDC n. 26, de 11 de maio de 2012 . Altera a Resolução RDC n.07, de 24 de fevereiro de 2019, que dispõe sobre os requisitos mínimos para funcionamento de Unidades de Terapia Intensiva e dá outras providências. Diário Oficial da União: República Federativa do Brasil; 2012. Apr. 15. Seção 1: p.170. (col. 3).

13. Park SH, Blegen MA, Spetz J, Chapman SA, De Groot HA. Comparison of nurse staffing measurements in staffing-outcomes research. Med Care. 2015; 53(1):e1-8. doi: 10.1097/MLR.0b013e318277eb50

14. Kelly DM, Kutney-Lee A, McHugh MD, Sloane DM, Aiken LH. Impact of critical care nursing on 30-day mortality of mechanically ventilated older adults. Crit Care Med. 2014;42(5):1089-95. doi: 10.1097/CCM.0000000000000127

15. Naves LK, Tronchin DMR. Incidence of gastric extubation of users in a home care program of a university hospital. Rev. Lat Am Enfermagem [Internet]. 2012 [cited 2016 Jul 20];20(3):543-50. Available from: http://dx.doi.org/10.1590/S0104-11692012000300016. English, Portuguese, Spanish.

16. Cervo AS, Magnago TS, Carollo JB, Chagas BP, de Oliveira AS, Urbanetto JS. Adverse events related to the use of enteral nutritional therapy. Rev Gaúcha Enferm [Internet]. 2014 [cited 2017 Oct 28];35(2):53-9. Available from: http://dx.doi.org/10.1590/1983-1447.2014.02.42396 . English, Portuguese.

17. Brugnolli A, Ambrosi E, Canzan F, Saiani L. Securing of naso-gastric tubes in adult patients: a review. Int J Nurs Stud. 2014;51(6):943-50. doi:10.1016/j.ijnurstu.2013.12.002

18. Bechtold ML, Nguyen DL, Palmer LB, Kiraly LN, Martindale RG, McClave SA. Nasal bridles for securing nasoenteric tubes: a meta-analysis. Nutr Clin Pract [Internet].2014[cited 2017 Oct 28];29(5):667-71. Available from:https://www.ncbi.nlm.nih.gov/pmc/articles/PMC4304091/ pdf/nihms654781.pdf

19. Bouza C, Garcia E, Diaz M, Segovia E, Rodriguez I. Unplanned extubation in orally intubated medical patients in the intensive care unit: a prospective cohort study. Heart Lung. 2007;36(4):270-6. doi: 10.1016/j.hrtlng. 2006.10.002 
20. Jarachovic M, Mason M, Kerber K, McNett M. The role of standardized protocols in unplanned extubations in a medical intensive care unit. Am J Crit Care [Internet]. 2011 [cited 2017 Oct 22];20(4):304-11. Available from: http://ajcc.aacnjournals.org/content/20/4/304.full.pdf+html

21. de Groot RI, Dekkers OM, Herold IH, de Jonge E, Arbous MS. Risk factors and outcomes after unplanned extubations on the ICU: a case-control study. Crit Care [Internet]. 2011 [cited 2017 Oct 20];15(1):R19. Available from:https://www.ncbi.nlm.nih.gov/pmc/articles/ PMC3222053/pdf/cc9964.pdf

22. da Silva, Fonseca MC. Unplanned endotracheal extubations in the intensive care unit: systematic review, critical appraisal, and evidencebased recommendations. Anesth Analg. 2012;114(5):1003-14. doi: 10.1213/ANE.0b013e31824b0296

23. Chang LC, Liu PF, Huang YL, Yang SS, Chang WY. Risk factors associated with unplanned endotracheal self extubation of hospitalized intubated patients: a 3-year retrospective case-control study. Appl Nurs Res. 2011; 24:188-92. doi: 10.1016/j.apnr.2009.09.002

24. Mehta NM, Sharma S, Laussen PC. Unplanned extubation: securing the tool of our trade. Intensive Care Med. 2015;41(11):1983-5. doi:10.1007/s00134-015-4000-1

25. Lorente L, Huidobro MS, Martín MM, Jiménez A, Mora ML. Accidental catheter removal in critically ill patients: a prospective and observational study. Crit Care. 2004;8(4):229-33.

26. Nascimento CC, Toffoletto MC, Gonçalves LA, Freitas Wd, Padilha KG. Indicators of healthcare results: analysis of adverse events during hospital stays. Rev Lat Am Enfermagem [Internet]. 2008 [cited 2017 Oct 28];16(4):746-51. Available from: http://dx.doi.org/10.1590/S010411692008000400015. English, Portuguese, Spanish.

27. Dekker SWA, Breakey B. 'Just culture': Improving safety by achieving substantive, procedural and restorative justice. Saf Sci [Internet]. 2016 [cited 2017 Oct 28];(85):187-93.Available from: http://dx.doi.org/10.1016/j.ssci.2016.01.018

28. Griffiths P, Ball J, Drennan J, Dall'Ora C, Jones J, Maruotti A, et al. Nurse staffing and patient outcomes: Strengths and limitations of the evidence to inform policy and practice. A review and discussion paper based on evidence reviewed for the National Institute for Health and Care Excellence Safe Staffing guideline development. Int J Nurs Stud. 2016;63:213-25. doi: 10.1016/j.jjurstu.2016.03.012

29. Johnson ML, Crown W, Martin BC, Dormuth CR, Siebert U. Good research practices for comparative effectiveness research: analytic methods to improve causal inference from nonrandomized studies of treatment effects using secondary data sources: the ISPOR Good Research Practices for Retrospective Database Analysis Task Force Report-Part III. Value Health. 2009;12(8):1062-73. doi: 10.1111/j.1524-4733.2009.00602.x. 